\title{
Erratum to: Dynamics of Simple Food Webs
}

\author{
Tomas Gedeon $^{1}$ • Patrick Murphy ${ }^{1}$
}

Published online: 11 February 2016

(C) Society for Mathematical Biology 2016

\section{Erratum to: Bull Math Biol DOI 10.1007/s11538-015-0106-4}

In the writing of the introduction we relied on an upcoming book chapter Beck et al. (2016), but the citation has been accidentally omitted in the submitted version of the paper.

\section{Reference}

Beck A, Hunt K, Bernstein H, Carlson R (2016) Interpreting and designing microbial communities for bioprocess applications, from components to interactions to emergent properties, chap. 15. In: Eckert $\mathrm{T}$ (ed) Biotechnology for biofuel production and optimization. Elsevier, Amsterdam, pp 407-432

The online version of the original article can be found under doi:10.1007/s11538-015-0106-4.

$\triangle$ Tomas Gedeon

gedeon@math.montana.edu

1 Department of Mathematics, Montana State University, Bozeman, MT 59717, USA 